\title{
PERCEPÇÃO AMBIENTAL DOS RESIDENTES DA CIDADE DE ASSIS - SP COM RELAÇÃO À ARBORIZAÇÃO VIÁRIA DA AVENIDA RUI BARBOSA.
}

\author{
Lorena Sério de Quadros $^{1}$, Fernando Frei ${ }^{2}$ \\ (recebido em 28.01.2009 e aceito para publicação em 25.06.2009)
}

\section{RESUMO}

O conceito de percepção ambiental sintetiza o processo de reunir e integrar informações que têm seqüência na cognição ambiental, ocorrendo uma avaliação pessoal que varia conforme o observador e as características do próprio ambiente. A qualidade ambiental urbana é um conjunto de condições materiais, sociais e psicológicas que maximizam o bem-estar humano nas cidades. Para um melhor planejamento e compreensão do ambiente urbano, fazem-se necessários estudos que enfoquem a percepção da população em relação ao meio ambiente, os quais podem ser utilizados como um instrumento de planejamento e gestão de áreas verdes. O presente trabalho tem como objetivo analisar a percepção ambiental da população com relação à inexistência da arborização viária da principal avenida no município de Assis - SP. Para tanto foram desenvolvidos alguns experimentos que envolviam a apresentação de fotografias da mesma área com e sem arborização associadas a um questionário. Entre os principais resultados obtidos destaca-se a percepção positiva da arborização, principalmente para os quesitos que influenciam diretamente no microclima urbano e, por conseqüência, a percepção da influencia da arborização viária no bem-estar físico e psicológico dos cidadãos. Esses resultados poderão ser utilizados como base para o desenvolvimento de projetos de gestão e educação ambiental urbanas.

Palavras-chave: Percepção ambiental, arborização urbana.

\footnotetext{
1.Discente do Curso de Ciências Biológicas - FCL Assis - UNESP. Lorena squadros@yahoo.com.br. Rua Bolívar Raimundo de Góes, 192 - Capivari/SP - CEP: 13360-000.

2.Docente Departamento de Ciências Biológicas - FCL Assis - UNESP - Laboratório de Estatística Aplicada. ffrei@assis.unesp.br
} 
ENVIRONMENTAL PERCEPTION OF RESIDENTS OF THE CITY OF ASSIS - SP WITH REGARD TO THE ARBORIZATION OF RUI BARBOSA AVENUE.

\begin{abstract}
The concept of environmental perception explain the process of integrate the informations that has sequency in the environmental knowledgement, accuring a self evaluation that vary depending on the observer and the environmental caracteristics. The quality of the urban environmental is an amount of material, social and psicological conditions that increase the human welfare in the cities. To increase the understanding of the urban environmental, making necessary studies that focus the perception of the population in relation to the environment, which can be used as a planning instrument and green areas management. The present work have as objective to analyze the population environmental knowledgement in relation to the lack of streets arborization in Assis - SP. Some experiments involving the apresentation of pictures from an area with and without arborization were developed in association to a questionary. In the main results acquired, the positive perception of the arborization were noticed, mainly the questions about the urban microenvironment and the influence of the arborization in the human psychological welfare. Those results can be used as a base to develop new education and urban environmental projects.
\end{abstract}

Key-words: environmental perception, urban trees. 


\section{INTRODUÇÃO}

Percepção é, por definição, o ato, efeito ou faculdade de perceber, adquirir conhecimento a partir de algo por meio dos sentidos, compreender, ouvir. Dessa maneira, a percepção apresenta como característica a aquisição de informações pelos atores sociais, oriundos da realidade do meio externo e de sua própria interação com o mundo material que os cerca. Assim, observa-se a percepção como um processo cognitivo-cultural, que envolve mecanismos de percepção externa - os cinco sentidos e a elaboração mental (AMANTE, 2001 apud ROPPA et al., 2007).

O termo percepção ambiental foi desenvolvido por Guifford (1987), apud Moniz, (1997) e, segundo o autor, é o processo de reunir e integrar informações que têm seqüência na cognição ambiental, onde ocorre uma avaliação pessoal que varia conforme o observador e as características do próprio ambiente.

O conceito de percepção ambiental pode significar a representação que uma determinada população tem sobre o seu meio ambiente, agregando a esse conceito termos como valores, identidade, interpretações sobre as relações e conhecimentos acumulados dos processos vitais (PACHECO e SILVA, 2006).

Nos últimos 20 anos, a percepção ambiental tem recebido destaque como técnica que associa a psicologia, geografia, biologia e ecologia com a sociologia e antropologia, auxiliando na compreensão de expectativas, satisfações e insatisfações da população em relação ao ambiente em que vive e no reconhecimento de fatores que afetam o bem estar e a qualidade de vida (SOARES, 2005).

Os estudos que enfoquem a percepção da população em relação ao meio ambiente devem ser utilizados como um instrumento que a administração municipal pode utilizar no planejamento e gestão de áreas verdes, atendendo a população através de políticas públicas, estabelecendo programas de educação ambiental e incentivando estudos acadêmicos na área (OLIVEIRA, 2005).

A vegetação, pelos vários benefícios que pode proporcionar ao meio urbano, teria um papel muito importante no restabelecimento da relação entre o homem e o meio natural, garantindo melhor qualidade de vida (UNESP/FCAV/FUNEP, 2002).

O espaço urbano é constituído, basicamente, por três entidades distintas, sendo elas áreas edificadas, áreas destinadas à circulação da população e áreas verdes de edificações como praças, quintais, etc. (OLIVEIRA, 2005).

Entende-se por arborização urbana toda a cobertura vegetal de porte arbóreo existente nas cidades. Essa vegetação ocupa, fundamentalmente, três espaços: as áreas livres de uso público e potencialmente coletivas, as áreas livres particulares e as áreas que acompanham o sistema viário (OLIVEIRA, 2005). 
Segundo Silva (1997) apud Santos (2008) a população, de maneira geral, costuma excluir a arborização das vias públicas como integrante da área verde da cidade, por considerar esta acessória e ter objetivos distintos das outras categorias de áreas verdes, uma vez que estas são destinadas principalmente à recreação e ao lazer e aquela tem finalidade estética, de ornamentação e sombreamento, além de propiciar um equilíbrio ambiental entre as áreas construídas e o ambiente natural alterado.

As áreas verdes urbanas contribuem para a melhora da qualidade de vida da população de diversas maneiras. Absorve ruídos, atenua o calor do sol, constitui-se em eficaz filtro das partículas sólidas em suspensão no ar, contribui para a formação e o aprimoramento do senso estético. Entre os benefícios ecológicos pode-se destacar a mitigação dos impactos da industrialização (LOBODA e DE ANGELIS, 2005). Por outro lado, entre os benefícios mentais estão a atenuação do sentimento de opressão e de distúrbios psicológicos; aprimoramento do censo estético e sentimento de tranqüilidade e harmonia com o meio circundante (OLIVEIRA e FERREIRA, 2005).

Além de todos os benefícios já citados, a arborização de ruas tem evidente importância para a integração das praças e parques, locais públicos de lazer, os quais devem proporcionar o bem-estar da população (GOMES e AMORIM, 2003), bem como garantir abrigo e alimentação para fauna, propiciando a manutenção de sua diversidade (BRUN et al., 2007).

O presente trabalho tem como objetivo analisar a percepção ambiental da população com relação à arborização viária da Avenida Rui Barbosa na cidade de Assis - SP, identificando e analisando o nível de bem-estar físico e psicológico dos cidadãos conforme a variação do nível de arborização desta. Pretende-se inaugurar esse tipo de estudo no município, uma vez que não há histórico de estudos em percepção ambiental.

\section{MATERIAIS E MÉTODOS}

\section{Localização do Município de Assis e condições climáticas}

Assis localiza-se na região oeste do Estado de São Paulo, sendo o centro da cidade situado a $22^{\circ} 39^{\prime} 42^{\prime \prime}$ de latitude e $50^{\circ} 24^{\prime} 44^{\prime \prime}$ de longitude, com uma população de 94.400 habitantes (SEADE, 2008).

O clima é temperado quente e a temperatura média anual apresenta valores iguais a $22^{\circ} \mathrm{C}$ chegando a $31^{\circ} \mathrm{C}$ nos meses de verão (média máxima) (CEPAGRI, 2009).

O município de Assis, localizado no Sudoeste Paulista possui uma população estimada de 95. 367 habitantes (SEADE, 2008).

A Avenida Rui Barbosa foi escolhida para o experimento de percepção ambiental por ser um grande centro de comércio do município, possuindo, por isso, um grande QPp? 
fluxo de pessoas e veículos e um excesso de poluição visual devido à propaganda irregular, além de estar situada em região com um dos mais baixos índices de abundancia arbórea (ROSSATTO et al. 2008).

\section{Descrição dos experimentos}

Para mensurar o nível de percepção ambiental da população de Assis - SP sobre a arborização viária da Avenida Rui Barbosa, um local foi escolhido para a realização das fotografias, feitas em dois momentos distintos. O local escolhido foi um trecho com excesso de poluição visual e nenhuma arborização.

A primeira fotografia foi feita em uma manhã de domingo - intitulada "domingo" sem movimentação no comércio, para que as fachadas das lojas e o excesso de propagandas e faixas pudessem aparecer de maneira adequada, sem o trânsito de pessoas e veículos no local (Figura 1). A segunda fotografia foi efetuada em uma tarde de movimento, com o comércio aberto, tendo por título "semana" (Figura 2).

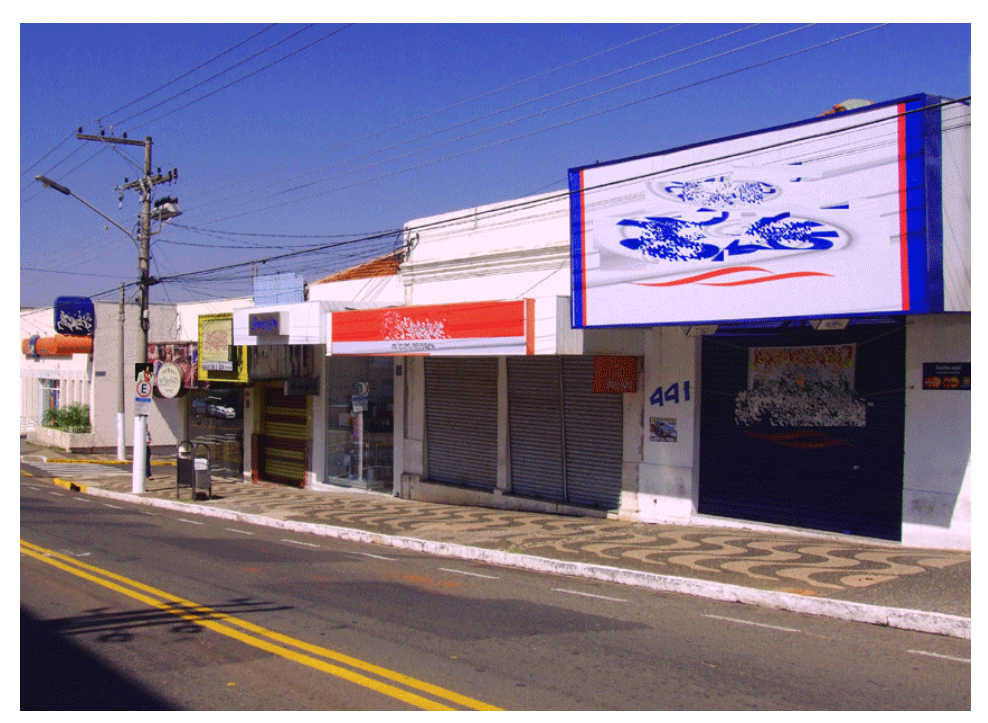

Figura 1: Foto original feita em manhã de domingo. 


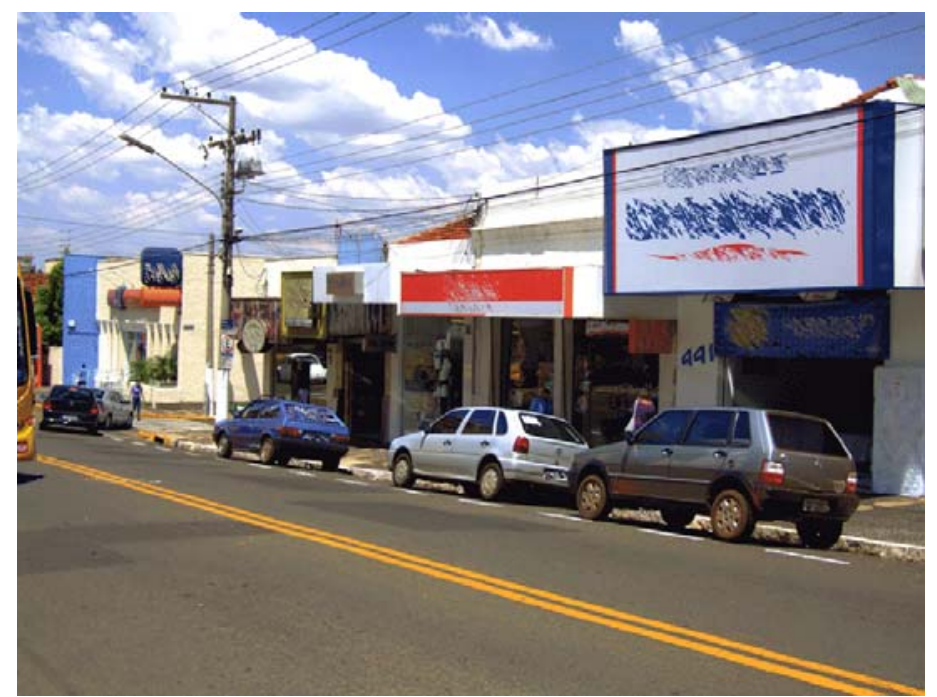

Figura 2: Foto original feita em tarde movimentada.

Em seguida, foram realizadas diversas fotografias de árvores presentes nas ruas da cidade, e estas foram utilizadas na etapa posterior, que consistiu em editar cada uma das fotografias, escondendo as propagandas irregulares e incluindo as árvores de maneira ordenada. (Figuras 3 e 4).

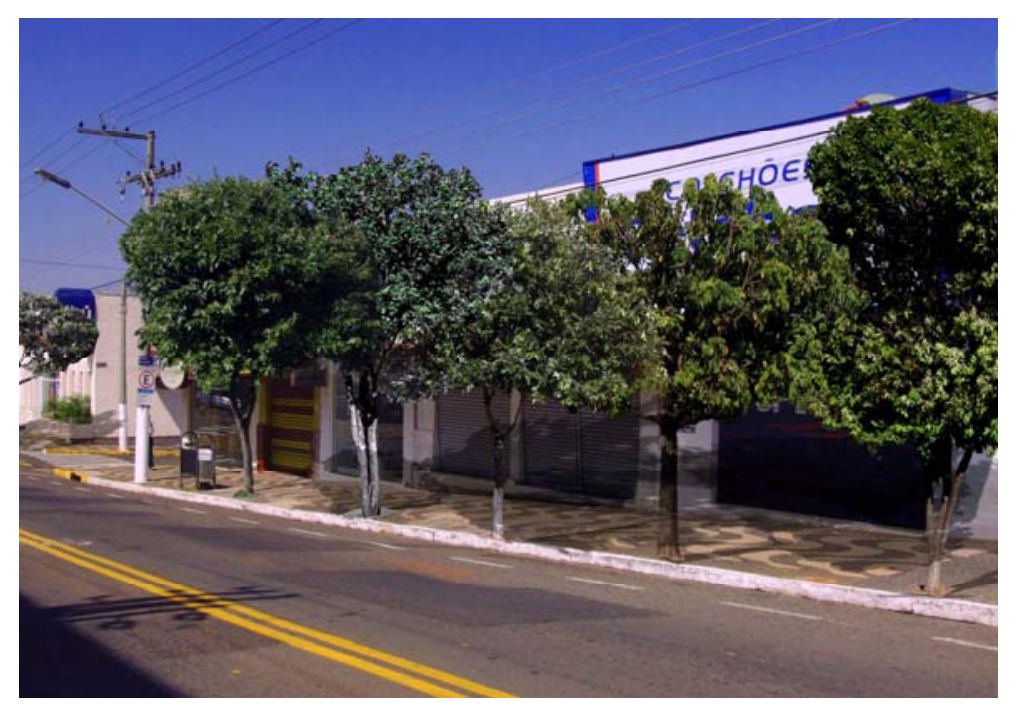

Figura 3: Foto editada feita em manhã de domingo. 


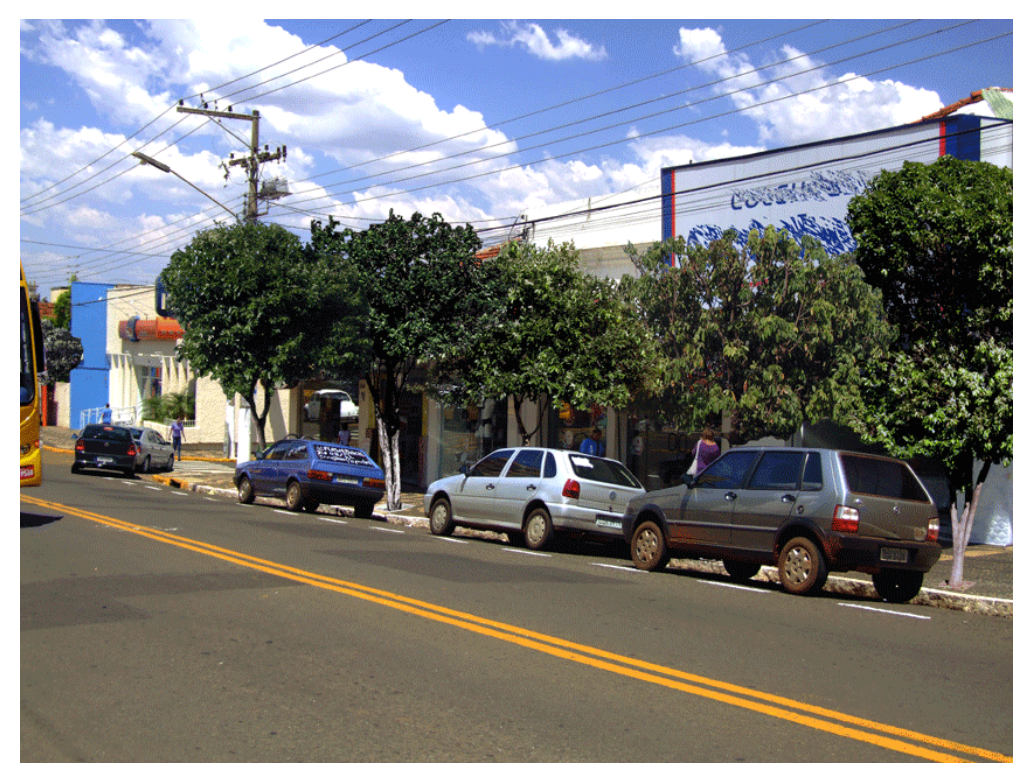

Figura 4: Foto editada feita em tarde movimentada.

O experimento 1 consistiu na apresentação da foto "semana" original para uma amostra de $n=100$ indivíduos e a editada para outra amostra de mesmo tamanho. O experimento 2 apresenta fotografias "semana" original e editada para o mesmo grupo de entrevistados $(n=100)$, alternando a ordem de apresentação das fotografias, de forma que a foto original é apresentada, ora em primeiro lugar, ora em segundo lugar. Os experimentos 3 e 4 constaram dos mesmos procedimentos mencionados anteriormente utilizando-se as fotografias "domingo" com 100 sujeitos em cada experimento.

Para mensurar a percepção ambiental, foi elaborado um instrumento de pesquisa - questionário, contendo questões fechadas. Neste instrumento foram coletadas variáveis que caracterizam a população quanto ao sexo e escolaridade. Todos os sujeitos participantes possuíam 15 anos ou mais de idade. (Anexo 1)

Metade das entrevistas de cada grupo foi feita na Avenida Rui Barbosa e metade em outras ruas.

\section{Descrição das análises}

Com os dados de todas as amostras dos quatro experimentos, foram utilizados os softwares livres Instat+ v3.36 e Biostat 5.0. As análises foram feitas utilizando testes de comparação de proporção para amostras independentes e dependentes (Macnemar), testes de Mann-Whitney e testes de Wilcoxon, teste Qui-quadrado e análises estatísticas descritivas. Todos os testes adotaram nível de significância igual a $5 \%$, em comparação com o valor $p$ obtido nas amostras. 


\section{RESULTADOS E DISCUSSÕES}

A amostra foi composta por $55 \%$ de indivíduos do sexo feminino e $45 \%$ do sexo masculino. As idades dos entrevistados variaram entre 14 anos e 78 anos (tabela 1). Pouco mais da Metade da amostra $(52,64 \%)$ foi composta por sujeitos com até 30 anos de idade.

Tabela 1. Distribuição das idades,

Assis - SP , 2009.

\begin{tabular}{lc}
\hline Idade (em anos) & $\%$ \\
\hline Menor que 21 & 22,98 \\
21 a 30 & 29,66 \\
31 a 40 & 15,37 \\
41 a 50 & 13,04 \\
51 a 60 & 10,56 \\
61 ou mais & 8,40 \\
\hline
\end{tabular}

Para a composição da amostra, foram entrevistados indivíduos de todas as categorias de escolaridades como mostra a figura 5.

Figura 5 . Escolaridade da amostra, Assis - SP, 2009.

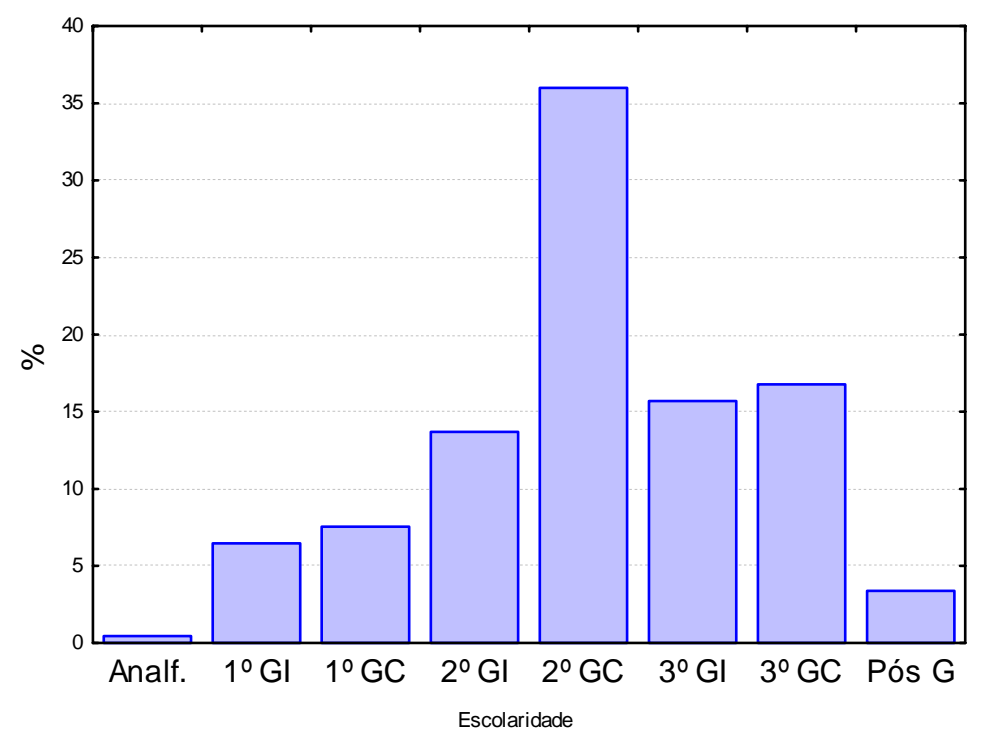

Todas as variáveis, sexo, idade e escolaridade, serviram como parâmetro de representatividade da população. Desta forma, as diversas camadas da população foram representadas na da pesquisa.

Através da metodologia aplicada para o presente trabalho, pode-se verificar que a população do município de Assis, de maneira geral, possui uma percepção ambiental 
favorável com relação à arborização da Avenida Rui Barbosa, dos entrevistados 97\% são favoráveis à arborização.

A arborização foi percebida de forma positiva com relação os quesitos ligados diretamente ao microclima urbano, tais como aumento da quantidade de sombra, melhoria da temperatura, ventilação e umidade (tabelas 2, 3 e 4).

Tabela 2. Experimento 1. Comparação de proporção (\%), foto editada e original para os quesitos da arborização viária relacionados diretamente com 0 microclima urbano. Assis - SP, 2008.

\begin{tabular}{cccc}
\hline Quesito & Foto & \% Percepção agradável & Teste proporção (p\%) \\
\hline \multirow{2}{*}{ Temperatura } & Original & 5,00 & 0,00 \\
& Editada & 63,00 & 0,00 \\
\multirow{2}{*}{ Umidade } & Original & 32,00 & \\
& Editada & 61,00 & 0,00 \\
\multirow{2}{*}{ Sombra } & Original & 2,00 & \multirow{2}{*}{0,00} \\
& Editada & 58,00 & \\
\hline
\end{tabular}

Tabela 3. Experimento 2. Comparação de proporção (\%), para a ordem de apresentação do tipo de fotografia para os quesitos da arborização viária relacionados diretamente com o microclima urbano. Assis - SP, 2008.

\begin{tabular}{|c|c|c|c|c|c|}
\hline \multirow[b]{2}{*}{ Quesito } & \multirow[b]{2}{*}{ Foto } & \multicolumn{2}{|c|}{ Original e Editada } & \multicolumn{2}{|c|}{ Editada e Original } \\
\hline & & $\begin{array}{c}\text { \% Percepção } \\
\text { agradável }\end{array}$ & $(p \%)^{\star}$ & $\begin{array}{c}\text { \% Percepção } \\
\text { agradável }\end{array}$ & $(p \%)^{*}$ \\
\hline \multirow{2}{*}{ Temperatura } & Original & 16,00 & \multirow{2}{*}{0,00} & 75,50 & \multirow{2}{*}{0,02} \\
\hline & Editada & 92,00 & & 0,00 & \\
\hline \multirow{2}{*}{ Umidade } & Original & 24,00 & \multirow{2}{*}{0,00} & 83,70 & \multirow{2}{*}{0,00} \\
\hline & Editada & 84,00 & & 2,00 & \\
\hline \multirow{2}{*}{ Sombra } & Original & 6,00 & \multirow{2}{*}{0,00} & 83,70 & \multirow{2}{*}{0,00} \\
\hline & Editada & 94,00 & & 2,00 & \\
\hline \multirow{2}{*}{ Ventilação } & Original & 26,00 & \multirow{2}{*}{0,00} & 87,80 & \multirow{2}{*}{0,00} \\
\hline & Editada & 90,00 & & 4,10 & \\
\hline
\end{tabular}

*Teste proporção (nível de significância adotado - 5\%)

A percepção agradável preponderante observada, nas tabelas 2 e 3, nos diversos quesitos na foto editada em relação à foto original, pode ser justificada pela 
ocorrência de altas temperaturas na cidade durante o verão, o que impulsiona a população a buscar meios que proporcionem um maior conforto térmico, principalmente em cidades em que a intensidade das chamadas ilhas de calor estão associadas a ausência de áreas verdes (COLTRI, et al.,2007)

Deve-se ressaltar que o resultado apresentado anteriormente não distingue o local em que o indivíduo pesquisado foi abordado, o que pode ampliar ou reduzir determinadas percepções. Desta forma, o resultado de 75\% para percepção agradável no quesito temperatura (tabela 3 ) traduz a opinião de indivíduos abordados em áreas arborizadas e não arborizadas. Por outro lado, a análise de resultados estratificados por categoria de arborização mostra a interação entre o estímulo da fotografia e a arborização existente.

A fotografia editada apresenta $82 \%$ de percepção agradável para o quesito temperatura quando o local da entrevista é categorizado como arborizado e $65 \%$ para locais não arborizados. Essa diferença percentual é minimizada quando a foto original é apresentada em regiões arborizadas, 23\% de percepção agradável, contra 20\% em regiões não arborizadas. A interação entre o estímulo e o meio amplia a percepção agradável da arborização urbana quanto à temperatura, no entanto a falta de estímulo, apresentada na fotografia não editada, não proporciona alterações estatisticamente significativas $(p>0,05)$ no quesito analisado.

De maneira geral, os quesitos ligados à poluição tiveram um nível de percepção menor, sendo que a maior percepção foi ligada à poluição visual e a menor, à sonora (tabelas 4 e 5).

Tabela 4. Experimento 1. Comparação de proporção (\%), foto editada e original para os quesitos da arborização viária relacionados com os tipos de poluição. Assis - SP, 2008.

\begin{tabular}{cccc}
\hline Quesito & Foto & $\begin{array}{c}\text { \% Percepção } \\
\text { agradável }\end{array}$ & $\begin{array}{c}\text { Teste proporção } \\
(\mathrm{p} \%)^{\star}\end{array}$ \\
\hline \multirow{2}{*}{ Poluição atmosférica } & Original & 58,00 & 38,75 \\
& Editada & 56,00 & \\
Poluição visual & Original & 18,00 & 0,67 \\
& Editada & 33,00 & 0,04 \\
\hline \multirow{2}{*}{ Poluição sonora } & Original & 56,00 & \\
\hline
\end{tabular}

*Teste proporção (nível de significância adotado - 5\%). 
Tabela 5. Experimento 2. Comparação de proporção (\%) para a ordem de apresentação do tipo de fotografia para os quesitos da arborização viária relacionados com os tipos de poluição. Assis - SP, 2008.

\begin{tabular}{|c|c|c|c|c|c|}
\hline \multirow[b]{2}{*}{ Quesito } & \multirow[b]{2}{*}{ Foto } & \multicolumn{2}{|c|}{ Original e Editada } & \multicolumn{2}{|c|}{ Editada e Original } \\
\hline & & $\begin{array}{c}\text { \% Percepção } \\
\text { agradável }\end{array}$ & $(p \%)^{*}$ & $\begin{array}{c}\text { \% Percepção } \\
\text { agradável }\end{array}$ & $(p \%)^{\star}$ \\
\hline Poluição & Original & 34,00 & \multirow{2}{*}{0,02} & 79,60 & \multirow{2}{*}{0,00} \\
\hline atmosférica & Editada & 66,00 & & 26,50 & \\
\hline \multirow{2}{*}{ Poluição visual } & Original & 18,00 & \multirow{2}{*}{0,00} & 61,20 & \multirow{2}{*}{0,00} \\
\hline & Editada & 60,00 & & 12,20 & \\
\hline \multirow{2}{*}{ Poluição sonora } & Original & 20,00 & \multirow{2}{*}{0,01} & 53,10 & \multirow{2}{*}{0,00} \\
\hline & Editada & 48,00 & & 22,40 & \\
\hline
\end{tabular}

*Teste proporção (nível de significância adotado - 5\%).

A menor percepção relacionada aos quesitos de poluição apresentados nas tabelas 4 e 5, pode ter ocorrido devido aos indivíduos se basearem apenas na observação visual e, portanto, as poluições atmosféricas e sonoras não foram devidamente percebidas. Outro fato importante a ser mencionado é que não houve manipulação da quantidade de poluição visual das imagens, sendo que a diferença nos resultados da percepção nesse quesito entre a fotografia original e editada pode ser explicada pelo fato de que a arborização encobriu placas e cartazes.

Setores do conhecimento científico consideram a poluição visual um fator de devastação urbana por ser prejudicial à definição da imagem da cidade e, em conseqüência disso, ao equilíbrio psíquico dos seus habitantes (GENTIL, 2008).

Dos quesitos relacionados ao bem estar psicológico, a maior percepção foi à relacionada ao estresse e a menor à beleza (tabelas 8, 9 e 10).

Tabela 6. Experimento 1. Teste de comparação para os quesitos da arborização viária relacionados ao bem estar psicológico. Assis - SP, 2008.

\begin{tabular}{|c|c|c|c|c|}
\hline Quesito & Foto & Mediana & $\mathrm{DI}$ & $p(\%)^{\star}$ \\
\hline \multirow{2}{*}{ Satisfação psicológica } & Original & 5,00 & 3,00 & \multirow{2}{*}{0,06} \\
\hline & Editada & 6,00 & 2,25 & \\
\hline \multirow{2}{*}{ Beleza da rua } & Original & 5,00 & 4,00 & \multirow{2}{*}{18,00} \\
\hline & Editada & 5,00 & 3,00 & \\
\hline \multirow{2}{*}{ Nível de estresse } & Original & 7,00 & 3,00 & \multirow{2}{*}{0,01} \\
\hline & Editada & 4,50 & 4,00 & \\
\hline
\end{tabular}

* Nível de significância adotado - 5\%. DI - Desvio Interquartílico. 
Tabela 7. Experimento 2. Teste de comparação para a ordem de apresentação do tipo de fotografia para os quesitos da arborização viária relacionados ao bem estar psicológico. Assis - SP, 2008.

\begin{tabular}{|c|c|c|c|c|c|c|c|}
\hline \multirow[b]{2}{*}{ Quesito } & \multirow[b]{2}{*}{ Foto } & \multicolumn{3}{|c|}{ Original e Editada } & \multicolumn{3}{|c|}{ Editada e Original } \\
\hline & & Mediana & DI & $p(\%)^{*}$ & Mediana & DI & $\mathrm{p}(\%)^{\star}$ \\
\hline Satisfação & Original & 4,00 & 3,00 & \multirow{2}{*}{0,01} & 8,00 & 2,00 & \multirow{2}{*}{0,01} \\
\hline psicológica & Editada & 8,00 & 2,75 & & 3,00 & 5,00 & \\
\hline Beleza & Original & 4,00 & 4,00 & \multirow{2}{*}{0,01} & 8,00 & 3,00 & \multirow{2}{*}{0,01} \\
\hline da rua & Editada & 8,00 & 2,75 & & 2,00 & 4,00 & \\
\hline \multirow{2}{*}{$\begin{array}{l}\text { Nível de } \\
\text { estresse }\end{array}$} & Original & 7,00 & 4,00 & \multirow[t]{2}{*}{0,01} & 2,00 & 4,00 & \multirow{2}{*}{0,01} \\
\hline & Editada & 3,00 & 4,00 & & 8,00 & 3,00 & \\
\hline
\end{tabular}

*Teste proporção (nível de significância adotado - 5\%). DI - Desvio Interquartílico.

Para os experimentos 3 e 4, os resultados obtidos foram semelhantes aos já discutidos anteriormente para os experimentos 1 e 2. Porém, de maneira geral, em todas as categorias, os experimentos 1 e 2 obtiveram níveis maiores de percepção, provavelmente por se tratar de um dia de semana, o que demonstra que a arborização pode auxiliar na melhoria ambiental, física e psicológica mesmo em dias mais movimentados.

No que tange a variável escolaridade, as diferentes categorias educacionais apresentam associação positiva para a fotografia editada e a percepção agradável do quesito temperatura (tabela 8).

Tabela 8. Resultados do teste

Qui-quadrado ( $\alpha=5 \%$ ).

\begin{tabular}{lcc}
\hline Escolaridade & $\chi_{o}^{2}$ & $p$ \\
\hline $1^{\circ} \mathrm{Grau}^{*}$ & 13,59 & 0,0002 \\
$2^{\circ} \mathrm{Grau}$ & 90,96 & 0,0000 \\
$3^{\circ} \mathrm{Grau}$ ** & 52,43 & 0,0000
\end{tabular}

* Inclui analfabetos.

** Inclui pós graduação.
Tabela 9. Percentagem de avaliações agradáveis - foto editada. Assis - SP, 2008.

\begin{tabular}{lcc}
\hline \multirow{2}{*}{ Quesitos } & \multicolumn{2}{c}{ Sexo } \\
Temperatura & 73,00 & 70,00 \\
\cline { 2 - 3 } Umidade & 72,00 & 72,00 \\
Ventilação & 76,00 & 74,00 \\
\hline
\end{tabular}

De forma semelhante, os percentuais para a percepção agradável para a foto editada são semelhantes quando a comparação é feita entre os sexos masculino e feminino (tabela 9). 


\section{CONCLUSÕES}

A população do município de Assis - SP demonstrou possuir uma percepção ambiental positiva com relação à arborização. Os quesitos relacionados à temperatura, umidade, sombra e ventilação apresentaram resultados favoráveis à arborização na principal avenida da cidade.

Os resultados deste trabalho devem servir para incentivar o poder público local a desenvolver um possível projeto de arborização da Avenida Rui Barbosa de maneira a atender aos anseios da população, servindo como base para o desenvolvimento de programas de conscientização e gestão ambiental.

Os dados obtidos serão apresentados em forma de artigo de divulgação científica visando a publicação em jornais e revistas da cidade e região, para que a população reflita sobre os resultados deste trabalho e sobre sua própria percepção ambiental.

\section{REFERÊNCIAS BIBLIOGRÁFICAS}

BRUN, F. G. K.; LINK, D; BRUN, E. J. O emprego da arborização na manutenção da biodiversidade de fauna em áreas urbanas. Revista da Sociedade Brasileira de Arborização Urbana, Piracicaba, v. 2, n. 1, p. 117-127, 2007.

CEPAGRI. Centro de Pesquisas Meteorológicas e Climáticas Aplicadas a Agricultura UNICAMP. Disponível em http://www.cpa.unicamp.br. Consultado em 10/03/2009.

COlTRI, P. P.; VELASCO, G. D. N.; POLIZEL, J. L.; DEMETRIO, V. A.; FERREIRA, N. J. Ilhas de Calor da estação de inverno da área urbana do município de Piracicaba, SP. In: XIII SIMPÓSIO BRASILEIRO DE SENSORIAMENTO REMOTO. Anais... Florianópolis, Brasil, 21-26 abril 2007. Anais.

GENTIL, P. A. B. Poluição visual é crime. Clubjus, Brasília - DF: 25 jan 2008. Disponível em: http://www.clubjus.com.br/?artigos\&ver=2.15031. Consultado em 04 fev 2008.

GOMES, M. A. S.; AMORIM, M. C. C. T. Arborização e conforto térmico no espaço urbano: estudo de caso nas praças públicas de presidente prudente (SP). Caminhos de Geografia,Presidente Prudente, 7(10)94-106, set. 2003. 
Percepção ambiental dos residentes...

LOBODA, C. R.; De Angelis, B. L. Áreas verdes públicas urbanas: conceitos, usos e funções. Ambiência - Revista do Centro de Ciências Agrárias e Ambientais, Guarapuava,V. 1 No 1 Jan/Jun. 2005.

MONIZ, A. A. Percepção de Alunos sobre o uso de cartazes nas paredes da Universidade de Brasília. 1997. (Série: Téxtos de Alunos da Disciplina Psicologia Ambiental). Brasília, DF: UnB, Laboratório de Psicologia Ambiental. Disponível em: www.psi-ambiental.net/textos/tapa1997Cartazes.htm. Consultado em 28 mar. 2008.

OLIVEIRA, E. Z. Percepção ambiental x arborização urbana dos usuários da avenida Afonso Pena entre as ruas Calógeras a Ceará em Campo Grande - MS. 2005.: Disponível em: http://www.repams.org.br/downloads/ARTIGO\%20DO\%20MESTRADO.pdf. Consultado em 28 mar. 2008.

OLIVEIRA, I. L.; FERREIRA, A. R. Arborização urbana, alterações das paisagens e biodiversidade, melhoria de qualidade de vida dos moradores de Cáceres - MT. In: VIII CONGRESSO IBERO-AMERICANO DE EXTENSÃO UNIVERSITÁRIA. Anais... Rio de Janeiro 27 a 30 de novembro de 2005.

PACHECO, E.; SILVA, H. P. Compromissos epistemológicos do conceito de percepção ambiental. 2006. Disponível em: http://www.ivt-rj.net/sapis/2006/pdf/EserPacheco.pdf. Consultado em: 17 jan. 2008.

ROPPA, C.; FALKENBERG, J. R.; STANGERLIN, D. M.; BRUN, F. G. K.; BRUN, E. J.; LONGHI, S. J. Diagnóstico da percepção dos moradores sobre a arborização urbana na vila estação colônia - bairro Camobi, Santa Maria - RS. Revista da Sociedade Brasileira de Arborização Urbana, Piracicaba, v. 2, n. 2, p. 11-30, jun. 2007.

ROSSATTO D.R.; TSUBOY, M.S.F.; FREI, F. Arborização urbana na cidade de Assis SP: Uma abordagem quantitativa. Revista da Sociedade Brasileira de Arborização Urbana, Piracicaba, v.3, n.3, set. 2008, p. 1-16.

SANTOS, A.S.R. Arborização Urbana. Disponível em: http://www.aultimaarcadenoe.com/index1.htm. Consultado em 20 jan 2008.

SEADE - Fundação Sistema Estadual de Análise de Dados. Secretaria de Economia e QPPP 
Planejamento. Disponível em: http://www.seade.sp.gov.br. Consultado em 28/11/2008.

SILVA FILHO, D F.; PIVETTA, K. Boletim acadêmico - Série arborização urbana. Jaboticabal (SP); UNESP/FCAV/FUNEP, 2002, 61 p.

SOARES, S. M. V. A percepção ambiental da população noronhense em relação à área de preservação ambiental. Recife, 2005. 96 f. Monografia - Pós Graduação em Gestão e Política Ambiental/UFRPE.

\section{ANEXO 1}

Questionário de avaliação da percepção ambiental dos cidadãos de Assis com relação á arborização da Avenida Rui Barbosa

Local da Entrevista: ( ) Rui Barbosa ( ) Outro Local Temperatura do dia:

Foto: Original ( ) Editada ( )

Caracterização do tempo: ( ) Nublado ( ) Parcialmente Nublado ( ) Ensolarado Caracterização do local da entrevista (1): ( ) Arborizado ( ) Parcialmente Arborizado ( ) Não arborizado

Caracterização do local da entrevista (2): ( ) Sombra ( ) Sol

Idade:

Sexo: ( ) masculino ( ) feminino

Escolaridade: $\quad\left(\right.$ ) $1^{\circ} \mathrm{GI} \quad(\quad) 1^{\circ} \mathrm{GC} \quad(\quad) 2^{\circ} \mathrm{GI} \quad(\quad) 2^{\circ} \mathrm{GC} \quad(\quad) 3^{\circ} \mathrm{GI} \quad$ ( ) $3^{\circ}$

GC ( ) Pós ( ) Analfabeto

Ao observar a rua apresentada na fotografia, responda:

Q1. A temperatura parece ser:
( ) muito fria
( ) fria
( ) fresca
( ) quente
( ) muito quente
( ) Desagradável
( ) Agradável

Q2. A umidade do ar parece ser:
( ) muito fria
( ) fria
( ) fresca
( ) quente
( ) muito quente
( ) Desagradável ( ) Agradável

Q3. A poluição atmosférica parece ser:

REVSBAU, Piracicaba - SP, v.4, n.2, p.16-34, 2009 
Percepção ambiental dos residentes...

( ) Nenhuma ( ) muito baixa ( ) baixa ( ) Regular ( ) alta ( ) muito alta

Q4. A quantidade de poluição visual parece ser:

( ) Nenhuma ( ) muito baixa ( ) baixa ( ) Regular ( ) alta ( ) muito alta

Q5. O nível de ruídos parece ser:

( ) Nenhuma ( ) muito baixo ( ) baixo ( ) Regular ( ) alto ( ) muito alto

Q6. Você considera a quantidade de sombra é: ( ) suficiente ( ) insuficiente

Q7. A ventilação parece ser:

( ) muito fria ( ) fria ( ) fresca ( ) quente ( ) muito quente
( ) Desagradável
( ) Agradável

Se estivesse caminhando na rua apresentada na foto, como você se sentiria com relação a (o)...

Q8. Satisfação psicológica? de 0 a 10 ( sendo 0 a pior situação e dez a melhor situação):

Q9. Beleza da rua? de 0 a 10 ( sendo 0 a pior situação e dez a melhor situação):

Q10. Nível de estresse? de 0 a 10 ( sendo 0 a melhor situação e dez a pior situação):

Q11. O que você acha da arborização apresentada na foto?
( ) insuficiente
( ) suficiente
( ) excessiva

Q12. Você acha necessária a arborização de ruas?
( ) $\operatorname{sim}$
( ) não
( ) indiferente 